\title{
Hepatotropic Viruses in the Brazilian Amazon: A Health Threat
}

\author{
Raymundo Paraná ${ }^{1}$, Ludmila Vitvitski ${ }^{2}$ and Joao Eduardo Pereira ${ }^{3}$ \\ ${ }^{1}$ Gastro-Hepatology Unit, University Hospital, Federal University of Bahia, Salvador, BA; ${ }^{2}$ INSERM, U 271, Lyon-France; ${ }^{3}$ Department of \\ Health - State University of Feira de Santana, Feira de Santana, BA, Brazil
}

\begin{abstract}
Viral Hepatitis B, C and D are a serious public health problem in Brazil and other South American countries, mainly in the Amazonian region. Despite the paucity of clinical and epidemiological studies, a high prevalence of Hepatitis viruses has often been described in this area. Genotype F of Hepatitis B and Genotype III of Hepatitis D have been found to be quite prevalent in this area and preliminary studies have implicated both genotypes in carcinogenesis and peculiar pathogenic liver mechanisms. Initial epidemiological studies have further demonstrated a high prevalence of Hepatitis $C$ in the western Brazilian Amazon. The geographic, cultural, ethnic and environmental aspects of this region may favor hepatotropic virus dissemination, as well as rendering difficult the implementation of governmental programs in the treatment of patients and prevention of disease dissemination.
\end{abstract}

Key-Words: Brazil, Amazonian, hepatitis viruses, South America.

\section{The Scope of the Problem}

The Amazon River region is located in the northern part of Brazil and includes areas of 7 Brazilian states (Acre, Amazonas, Amapá, Pará, Rondônia, Roraima and Tocantins).

The region comprises 5.2 million $\mathrm{km}^{2}$ ( $61 \%$ of the Brazilian territory), a population of $18,748.490$ inhabitants (11.9\% of the Brazilian population) and a demographic density of 3.67 inhabitants $/ \mathrm{km}^{2}$. In the last two decades, the region has suffered a demographic expansion leading to a population increase of $128 \%$ where about $40 \%$ of the inhabitants are found in the rural area. It is a region of difficult access and low social development indexes.

The socioeconomic, communal and cultural peculiarities, which reflect the geographic and historic characteristics of the region, have consequences in the clinical-epidemiological aspects of the major prevalent diseases in this area. Thus, we have found as endemic, diseases such as malaria, yellow fever, leptospirosis, typhoid fever and viral hepatitis. One observes a high child mortality index due to infectious-contagious and immunopreventable diseases, indicating a major deficiency in the health system of the region.

Despite notable progress in the Brazilian Public Health System as implemented in the last decade, viral hepatitis is still an important public health problem. Furthermore it is a specific challenge for tropical medicine in the Brazilian Amazon region, where the morbidity-mortality rates for viral hepatitis are high.

In Brazil, particularly in the Amazon region, the mortality rates due to infectious-contagious diseases have dramatically reduced in the last decade, except for viral hepatitis (hepatitis C has presented a $30 \%$ increase in the mortality rate in the last

Received on 20 December 2007; revised 6 May 2008.

Address for correspondence: Dr Raymundo Paraná. Av. Juracy Magalhães Jr., 2096, sala 510. Zip code: 41920-000. Salvador, BA, Brazil. E-mail: rparana@ufba.br. This paper reports results from the Brazil/France hepatitis study group supported by the Brazilian Agency for Research (CNPq) and the French Institute of Medical Research (INSERM).

The Brazilian Journal of Infectious Diseases 2008;12(3):253-256. (C) 2008 by The Brazilian Journal of Infectious Diseases and Contexto Publishing. All rights reserved. decade). The distribution of the hepatitis $\mathrm{C}$ virus is not uniform in the region, changing according to geographic aspects (higher prevalence in the western Amazon), social aspects (variation according to income distribution) and ethnical aspects (high prevalence among some Amerindian ethnic groups, for example the "Vale do Javari” indigenous communities, where about $20 \%$ of the Indians are HBV carriers). Recently, Hepatitis $C$ virus circulation was identified in the region and, with little data, the evidence points to an important epidemiological impact of this virus in the region, where frequencies of up to $5.5 \%$ are found among some populations.

Different viral hepatitis are the main causes of Acute Icterus-hemorrhagic Fever Syndrome in the Amazon region. They are the cause of about $90 \%$ of deaths in the region, mostly among Amerindian ethnic groups.

The Brazilian government supplies the Public Health System with the vaccine and the immunoglobulin against the hepatitis B virus. These therapeutic materials, when properly used, may avoid viral transmission from mother to child. However, these resources are not widely used in this area due to the absence of professionals trained in their adequate usage.

In 2002, the Brazilian government, via the Ministry of Health, created the National Viral Hepatitis Program, which developed prevention, surveillance and assistance actions in the viral hepatitis field. It is estimated that there are 2 million HBV and 3 million HCV carriers in Brazil. The vast majority of these people live in the northern region, where it is very difficult to implement prevention and assistance actions, thus favoring the maintenance and dissemination of these viruses. The Brazilian Public Health System finances the entire treatment for viral hepatitis, although only a part of the resources actually reach the northern region (the Amazon region). In 2004, the Brazilian Ministry of Health spent U\$ 136.358,05 in the management of viral hepatitis, however, less than $5 \%$ of these resources were applied in the Amazon region.

The establishment of prevention and assistance actions for viral hepatitis in the Amazon region faces two great obstacles: 1 ) the absence of data on the local epidemiological 
behavior of the endemic and its socio-cultural interactions with the local population; 2) the lack of human resources technically capable of implementing clinical prevention protocols, diagnosis and treatment of viral hepatitis. The number of professionals is low and many of them do not possess the technical knowledge required for the management of viral hepatitis [1].

\section{Epidemiological Data}

Hepatitis B, D and C are still research priorities in Tropical Medicine, mainly in the Brazilian Amazon [2].

The route of transmission of these viruses and their epidemiological and virological peculiarities need to be studied in the different areas of the Amazon due to ethnic, genetic, environmental and cultural diversity.

The progress of molecular biology, has led to a better understanding of the association between the genetics of viruses and the natural history of the disease. It is clear now that HBV, HDV and HCV genotypes modulate disease severity and response to antiviral treatment [3-5].

In the Western Amazon the climate is humid tropical and the population, in spite of the best Human Development Index (HDIs), has a history of frequent contacts with unique environmental conditions. In this population, there is a high and unexplained HBV, HDV and HCV prevalence [6].

Recently, this region has initiated an ambitious vaccination program against HBV the impact of which will only be measurable after at least a decade. It is necessary to recognize today, the epidemiological reality of HBV for comparative and cost-benefit studies of field vaccination programs [7].

In Brazil, there is a paucity of studies concerning the prevalence of hepatitis B, D and C, even so, reports from the Ministry of Health undersign the high incidence of acute and chronic viral hepatitis in this area [8].

More recently, Viana et al. (2004) confirmed the high prevalence of HBV and HDV in 12 counties of the state of Acre. The HBsAg prevalence varied from $3 \%$ to $20 \%$ of the population. HDV infection was detected in $20 \%$ of $\mathrm{HBV}$ carriers, indicating that HDV is spreading in the Brazilian Amazon region. In addition, it has been demonstrated that Genotype F and A are prevalent in this population [9].

In this same area, Lobato et al. (2006) showed intrafamilial transmission to be the most important route of $\mathrm{HBV}$ dissemination in Acre. Once more, the high prevalence of genotype A and $\mathrm{F}$ was reported [10].

In Acre and Rondônia, the most western Amazonian states in Brazil, hepatitis D is still an important public health problem. Our group studied 40 patients in referral centers for liver disease in both states and could demonstrate that Genotype I and III of Delta viral hepatitis prevails in this region. Carriers of HDV genotype III were younger and more symptomatic when compared to carriers of genotype I [11].

Prevalence of $\mathrm{HCV}$ in Brazil suggests rates in the range of 1 to $1.5 \%$, in southern and north eastern regions, comparable to what is observed in Europe [12]. In contrast, the HCV prevalence in the Brazilian Amazonian seems to be higher. Paiva et al. (2006), who studied health care workers in Rio Branco, the capital of the Acre state, reported $4.5 \%$ of $\mathrm{HCV}$ prevalence, but genotype distribution was almost the same as that observed in less endemic and non-Amazonian areas of the country [13].

\section{Hepatitis as a Serious Continental Problem in South America With a Peculiar HBV Genotype F and HDV Genotype III}

Viral hepatitis is also an important public health problem in other South American Countries, where prevailing socioeconomic and cultural determinants favour the spread of its viruses [14].

The Western Amazon region is known to be a hyper endemic area for HBV and HDV, especially among Amerindian populations, which appear to be highly exposed to these viruses in Peru, Bolivia, Venezuela and Colombia [15,16].

This contrasts the observations in developed countries where HBV and HDV are under control following vaccination programs. HDV is spreading in the Amazon Basin, probably due to immigration and new contacts within the Amerindian population. More cases of HDV have been described outside hyper endemic areas, in the areas surrounding the Amazon $[17,18]$.

Vaccination programs have been conducted in Brazil. The Acre State (the most western Brazilian Amazon State) launched a vaccination program against $\mathrm{HBV}$, which supposedly covered $90 \%$ of the population. However, the use of the HBV vaccine is still not widespread in other South American countries, mainly those located in the Amazonian Basin.

In part, the lack of vaccination programs occurs due to cost issues and logistical problems of delivery (such as transport, cold chain maintenance, availability of trained personnel, etc.) in remote areas of this region and because their populations, due to social and educational reasons, do not have access to public health services.

The treatment of HBV and HCV is available on the public health system in Brazil, but this is not the reality in many other South American countries.

For both HBV and HCV, access to therapy is limited by drug costs (Interferon, Lamivudine, Entecavir, Adefovir for $\mathrm{HBV}$; peg-interferon and Ribavirin), as well as the lack of access to virological tools for monitoring the treatment efficacy or viral drug resistance. Virological diagnosis access for $\mathrm{HBV}$ and HCV is indeed an actual and serious problem in Brazil, especially in the Brazilian Amazon. Although there has been a rapid improvement in hepatitis $\mathrm{B}$ and $\mathrm{C}$ treatment in Brazil during the last 4 years, structural problems, mainly in the scope of biomolecular tests, still remain [19].

For HDV, the situation is even worse, as the only clinical information available comes from cases of fulminant hepatitis outbreaks in the Amazonian Basin.

In addition, the Amazon is the only region where genotype III of HDV has been found. This genotype seems to be more aggressive and is frequently associated with a more severe 
disease. Very few studies have been dedicated to this peculiar genotype. Many cases of fulminant hepatitis are annually described in the Amazon Basin, mainly in young people who live in the forest or in areas surrounding small towns [20-22].

In Brazil, as well as in other South American countries, insufficient data are available concerning viral hepatitis treatment and drug resistance. This is a worrisome situation, since treatment with antiviral drugs (Lamivudine, Adefovir and Tenofovir) is available on the Brazilian public health system, but without the possibility of screening for drug resistant viral strains.

\section{The Problem of Fulminant Hepatitis in the Amazon}

A mysterious disease, which accompanies liver failure with haemorrhage and rapid death, is frequently reported among the population of the Amazon Region and has been observed since the 1930's (Data not published).

In the 1970's Barberino and colleagues studied some of the patients with this severe disease and, from necropsies, the necessary materials for the characterization of the clinical and histopathological aspects were obtained (Data not published).

In the 80's a strong association between this syndrome and co-infection with hepatitis B and Delta was documented in this same region.

The hallmark of this disease is the presence of ballooned hepatocytes with a central nucleus surrounded by fat drops. Brazilian pathologists call this "morula - like" cells and French pathologists prefer the term "spongiocytes" [23,24].

During this same period, Lesbordes et al. (1987) described the existence of a similar disease associated to the HBV/Delta co-infection, in the Central African Republic, also situated in the equatorial forest [25].

Evaluation of these samples confirmed the strong similarity between these two viral infections. Later, Andrade et al. (1992) further concurred that the liver samples from both the Amazonian and the African infections shared identical histopathology [26].

Casey et al. (1997) have shown that in Latin America the super infection with genotype III of the Delta virus in HBV carriers of genotype $\mathrm{F}$ was present in almost all-typical histopathological cases [27].

On the other hand, when studying the Bangui cases we found genotype II of the Delta virus to be predominant in the Central African cases. However, this genotype contained mutations that affected the interaction between HBV and Delta with subsequent putative repercussions in viral pathogenicity [28].

Paraná et al. (1995) reproduced, experimentally, a similar disease, by inoculating patient sera into American woodchucks (M. Monax) carriers of WHV, the woodchuck hepatitis virus. These studies further reinforced the possibility that this fulminant disease was caused by the superinfection of HBV carriers with the Delta virus [29].

Up to now, there has been no specific treatment recommended for this syndrome. Taking advantage of studies that have shown some benefit from early Lamivudine therapy for fulminant hepatitis B, we propose the use of this drug in all cases of fulminant hepatitis followed in these referral centers. The safety of Lamivudine and the severity of this syndrome (almost $100 \%$ mortality) justify this proposal [30].

\section{The Problem of Hepatocellular Carcinoma}

Hepatocellular carcinoma (HCC) is a growing actual problem in the Amazon. From the rare epidemiological studies available, it would seem that most referral centers witness many cases of HCC, mostly in young people, even teenagers. In general, the diagnosis is confirmed at an advanced stage of HCC with very few, if any, therapeutic options.

This could be explained by HBV infection during childhood, but other possibilities must be studied such as the role of genotype $\mathrm{F}$, which could have a greater oncogenic role as suggested recently in the Eskimo population, where this particular genotype also prevails and/or the genetic background of Amerindians [31]. Here again, the role of HDV co-infection must be investigated [32].

In summary, hepatotropic viruses, mainly hepatitis B, remain a serious health threat in Brazil and South America. The Amazonian region, particularly, has the highest prevalence of hepatitis B and also faces hepatitis D as a spreading disease, in contrast with other Brazilian and South American regions [33].

\section{Acknowledgement}

The authors thank CNPq (Brazil) and INSERM (France), as well as the Brazilian program for viral hepatitis (PNHV) of the Brazilian Health Ministry.

\section{References}

1. Brasil. Ministério da Saúde/Programa Nacional de Hepatites Virais. Hepatites Virais: O Brasil está Atento. 2002.

2. de Paula V.S., Arruda M.E., Vitral C.L., Gaspar A.M. Seroprevalence of viral hepatitis in riverine communities from the Western Region of the Brazilian Amazon Basin. Mem Inst Oswaldo Cruz 2001;96(8):1123-8.

3. Fried M.W. Clinical application of hepatitis C virus genotyping and quantitation. Clin Liver Dis 1997;1(3):631-46.

4. Nakano T., Shapiro C.N., Hadler S.C., et al. Characterization of hepatitis D virus genotype III among Yucpa Indians in Venezuela. Gen Virol 2001;82:2183-9.

5. Hui A.Y., Chan H.L., Cheung A.Y., et al. Systematic review: treatment of chronic hepatitis B virus infection by pegylated interferon. Aliment Pharmacol Ther 2005;22(6):519-28.

6. Braga W.S., Brasil L.M., Souza R.A., et al. The occurrence of hepatitis B and delta virus infection within seven Amerindian ethnic groups in the Brazilian western Amazon. Rev Soc Bras Med Trop 2001;34:349-55.

7. Tavares-Neto J., Almeida D., Soares M.C., et al. Seroprevalence of hepatitis B and C in the Western Brazilian Amazon region (Rio Branco, Acre): a pilot study carried out during a hepatitis B vaccination program. Braz J Infect Dis 2004;8(2):133-9.

8. Brasil. Ministério da Saúde/Gerência de Doenças Emergentes e Reemergentes. Vigilância das Síndromes Febris Ictéricas e/ou Hemorrágicas Agudas: A Experiência Brasileira. Relatório de atividades apresentado a OPAS. 2002. 
9. Viana S., Parana R., Moreira R.C., et al. Prevalence of hepatitis B virus and hepatitis D virus in the western Brazilian Amazon. Am J Trop Med Hyg 2005;73(4):808-14.

10. Lobato C., Tavares-Neto J., Rios-Leite M., et al. Intrafamilial prevalence of hepatitis B virus in Western Brazilian Amazon region: epidemiologic and biomolecular study. J Gastroenterol Hepatol 2006 May;21(5):863-8.

11. Parana R., Kay A., Molinet F., et al. HDV genotypes in the Western Brazilian Amazon region: A preliminary report. Am J Trop Med Hyg 2006;75(3):475-9.

12. Silva L., Parana R., Mota E., et al.Prevalence of hepatitis $C$ virus in urban and rural populations of northeast Brazil-pilot study. Arq Gastroenterol 1995;32(4):16871.

13. Tiago Paiva, José Tavares-Neto, Márcio Rio-Leite, et al. HCV infection in health professionals from Western Brazilian Amazonia. Am J Trop Med Hyg 2007; [in press].

14. Parana R., Almeida D. HBV epidemiology in Latin America. J Clin Virol 2005;34 Suppl 1:S130-3.

15. Bensabath G., Dias L.B. [Labrea hepatitis (Labrea black fever) and other fulminant forms of hepatitis in Sena Madureira, Acre and Boca do Acre, Amazonas, Brazil]. Rev Inst Med Trop Sao Paulo 1983;25(4):182-94.

16. Fonseca J.C. [Hepatitis D]. Rev Soc Bras Med Trop 2002;35(2):181-90.

17. Gaeta G.B., Stroffolini T., Chiaramonte M., et al. Chronic hepatitis D: a vanishing Disease? An Italian multicenter study. Hepatology 2000;32(4 Pt 1):824-7.

18. Ribeiro L.C., Souto F.J. [Hepatitis Delta in the State of Mato Grosso, Brazil: report of 5 cases]. Rev Soc Bras Med Trop 2000;33(6):599-602.

19. Figueiredo G., Barbosa J. Hepatites Virais: o Brasil está atento. Gazeta Mádica da Bahia 2006;1(76)Sup1:1-4.

20. Casey J.L., Brown T.L., Colan E.J., et al. A genotype of hepatitis $D$ virus that occurs in northern South America. Proc Natl Acad Sci U S A 1993;90(19):9016-20.

21. Quintero A., Uzcategui N., Loureiro C.L., et al. Hepatitis delta virus genotypes I and III circulate associated with hepatitis B virus genotype F In Venezuela. J Med Virol 2001;64(3):356-9.
22. Manock S.R., Kelley P.M., Hyams K.C., et al. An outbreak of fulminant hepatitis delta in the Waorani, an indigenous people of the Amazon basin of Ecuador. Am J Trop Med Hyg 2000;63(34):209-13.

23. Bensabath G., Hadler S.C., Soares M.C., et al. Hepatitis delta virus infection and Labrea hepatitis. Prevalence and role in fulminant hepatitis in the Amazon Basin. JAMA 1987;258(4):479-83.

24. Lesbordes J.L., Ravisse P., Georges A.J., et al. Studies on the role of HDV in an outbreak of fulminant hepatitis in Bangui(Central African Republic). Prog Clin Biol Res 1987;234:451-9.

25. Lesbordes J.L., Ravisse P., Georges A.J., et al. [Role of delta viruses in fulminating hepatitis in Central Africa] Ann Med Interne (Paris) 1987;138(3):199-201.

26. Andrade Z.A., Lesbordes J.L., Ravisse P., et al. Fulminant hepatitis with microvesicular steatosis (a histologic comparison of cases occuring in Brazil - Labrea hepatitis - and central Africa - Bangui hepatitis). Rev Soc Bras Med Trop 1992;25:155-60.

27. Casey J.L., Niro G.A., Engle R.E., et al. Hepatitis B virus (HBV)/ hepatitis D virus (HDV) coinfection in outbreaks of acute hepatitis in the Peruvian Amazon basin: the roles of HDV genotype III and HBV genotype F. J Infect Dis 1996;174(5):920-6.

28. Tang J.R., Hantz O., Vitvitski L., et al. Discovery of a novel point mutation changing the HDAg expression of a hepatitis delta virus isolate from Central African Republic. J Gen Virol 1993;74(Pt 9):1827-35.

29. Paraná R., Gerard, F., Lesbordes J.L., et al.. Serial transmission of spongiocytic hepatitis to woodchucks (a possible association with a specific delta strain). J Hepatol 1995;22:468-73.

30. Santantonio T., Mazzola M., Pastore G. Lamivudine is safe and effective in fulminant hepatitis B. J Hepatol 1999;30(3):551.

31. Livingston S.E., Simonetti J.P., McMahon B.J., et al. Hepatitis B virus genotypes in Alaska native people with hepatocelular carcinoma: preponderance of genotype f. J Infect Dis. 2007;195(1):5-11. Epub 2006 Nov 21.

32. Miranda E.C., Moia L. de J., Amaral Ido S., et al. Hepatitis B and C virus infection and the hepatocellular carcinoma in the East Amazon, Brazil. Rev Soc Bras Med Trop 2004;37 Suppl 2:47-51.

33. Gish R.G., Gadano A.C. Chronic Hepatitis B: current epidemiology in the Americas and implications for management. J Vir Hepatitis 2006;13:787-98. 